\title{
Survey on Satisfaction with Korean Medicine Treatment and Motives for Visiting Korean Medicine Hospital for Cancer Patients: Report of 100 Cases
}

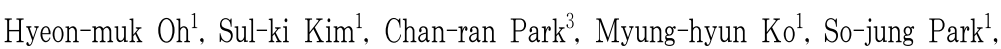
Chong-kwan Cho, Ji-hye Park ${ }^{2}$, Hwa-seung Yoo ${ }^{2}$ Nam-hun Lee ${ }^{3}$, Chang-gue Son ${ }^{1}$, Jung-hyo Cho

'Dept. of Internal Medicine, Daejeon Korean Medicine Hospital of Dae-Jeon University

${ }^{2}$ Dept. of Internal Medicine, Seoul Korean Medicine Hospital of Dae-Jeon University

${ }^{3}$ Dept. of Internal Medicine, Cheonan Korean Medicine Hospital of Dae-Jeon University

\section{Survey on Satisfaction with Korean Medicine Treatment and Motives for Visiting Korean Medicine Hospital for Cancer Patients: Report of 100 Cases}

\author{
Hyeon-muk Oh${ }^{1}$, Sul-ki Kim¹, Chan-ran Park ${ }^{3}$, Myung-hyun Ko․, So-jung Park ${ }^{1}$, \\ Chong-kwan Cho, Ji-hye Park ${ }^{2}$, Hwa-seung Yoo ${ }^{2}$ Nam-hun Lee ${ }^{3}$, Chang-gue Son', Jung-hyo Cho \\ 'Dept. of Internal Medicine, Daejeon Korean Medicine Hospital of Dae-Jeon University \\ ${ }^{2}$ Dept. of Internal Medicine, Seoul Korean Medicine Hospital of Dae-Jeon University \\ ${ }^{3}$ Dept. of Internal Medicine, Cheonan Korean Medicine Hospital of Dae-Jeon University
}

\section{ABSTRACT}

Objectives: This study aimed to evaluate the degree of satisfaction of cancer patients and to understand their motives for visiting Korean Medicine Hospital in order to increase satisfaction with Korean medicine among cancer patients.

Methods: Data collection was conducted in the form of a survey of 100 inpatients who responded to a self-report questionnaire. Independent $t$-test and analysis of variance (ANOVA) were used for data analysis.

Results: The main reason for visiting Korean Medicine Hospital was to prevent metastasis or recurrence of cancer. Patients showed the highest satisfaction with acupuncture and moxibustion. The average degree of satisfaction related to the doctor service was, on a 5-point scale, 4.80, and that of using procedure was 4.68 .

Conclusion: Most of the cancer patients are satisfied with the medical services in Korean Medicine Hospital. There were no significant differences in satisfaction degree by gender, age, or occupation.

Key words: patient satisfaction, Korean medicine, cancer

· 투고일: 2021.09.02, 심사일: 2021.09.29, 게재확정일: 2021.09 .29

- Corresponding author: Jung-hyo Cho Dept. of Internal Medicine, Korean Medicine Hospital of Daejeon University, Daedeok-daero 176 beon-gil 75, Seo-gu, Daejeon, Korea TEL: 042-470-9161 FAX: 042-470-9005 E-mail: choajoa@dju.ac.kr

\section{Introduction}

Cancer can be considered as the first and leading public health issue, which poses the highest clinical, social, and economic burden'. The number of cancer 
Survey on Satisfaction with Korean Medicine Treatment and Motives for

Visiting Korean Medicine Hospital for Cancer Patients: Report of 100 Cases

survivors continues to increase because of advances in early detection and treatment ${ }^{2}$. However, despite tremendous efforts to conquer cancer, there are still limitations in treating for end-stage cancer and various types of cancers, and is also a problem of side effects from surgery and chemotherapy ${ }^{3}$. Therefore, interest in complementary and alternative medicine for treating cancer is increasing worldwide ${ }^{4}$.

Cancer patients are choosing various treatments options such as Korean Medicine treatment in addition to standard treatment in Korea. According to one study, it was found that $31 \%$ of all cancer patients use Korean medicine treatment in Korea ${ }^{5}$. Various researches on cancer treatment using Korean medicine are being conducted in Korea, for example, cancer regression and angiogenesis inhibition ${ }^{6}$. In addition, many studies have been published that reporting the effect of improving the quality of life and treating side effects after chemotherapy, radiation, and surgery through Korean medicine treatment ${ }^{7.8}$.

For the development of Korean medicine cancer treatment, it will be helpful to establish the direction of research on cancer through assessment of the motives for choosing Korean medicine hospital and satisfaction of Korean medicine cancer treatment by patients. Despite this necessity, the evaluation data on Korean medicine cancer treatment are very scarce. In one study, the satisfaction of cancer patients who visited Korean medicine hospitals was reported, but the number of participants was small and it was only conducted in one institution'.

Therefore, we conducted this study to investigate the satisfaction of cancer patients who received inpatient treatment at Korean medicine hospital by surveying the motives of visiting the hospital and the satisfaction of medical services.

\section{Methods}

\section{Research setting and data collection}

This study was conducted on 100 inpatients who were admitted for cancer therapy in three Korean Medicine Hospital (Cheonan, Daejeon, Seoul) of Daejeon University during the period of November 2020 to May 2021.

Study participants were selected as patients who can communicate and respond to questionnaires. Sample selection limited to those who had been hospitalized for more than 3 days considering that the 2 days were judged as a period of adaptation to the hospital environment, medical staff and facilities. The protocol was approved by the institutional review board in Daejeon Korean Medicine Hospital (institutional review board number : DJDSKH20-E-36).

\section{Method}

We used modified and supplemented version of questionnaire developed by Park et al $(2015)^{9}$ which is a similar study to measure the satisfaction of cancer patients' medical service. and. After explaining the questionnaire for inpatients, the consent was obtained from participants. The patients received the questionnaire the previous day before being discharged and returned it before leaving hospital.

The questionnaire was composed of a total of 18 questions, including three major parts (1) demographic characteristics, (2) use-related characteristics, (3) medical service satisfaction. The detailed items of medical service satisfaction are 5-questions on satisfaction with doctor services and 5-questions on medical use procedures. Each satisfaction score was composed of a 5-point scale, and the higher the score, the higher the satisfaction was evaluated. 


\section{Statistical analysis}

Statistical analysis was performed using SPSS version 28.0 software for Windows (SPSS, Chicago, IL, USA). Collected data were computerized using Microsoft Excel software (Microsoft, Redmond, WA, USA) and non-responded items were excluded from analysis. Demographical characteristics were quantified with frequencies and percentages. For motivation and satisfaction for medical service, the mean and standard deviation were calculated and analyzed. To figure out the satisfaction of the medical service of cancer patients using Korean Medicine Hospital, mean and standard deviation were calculated. In order to find out the difference in satisfaction of medical service according to the general characteristics and use-related characteristics, independent $t$-test ( $t$-test), analysis of variance (ANOVA) were used for analysis. A significance level of 0.05 was used throughout. Internal consistency of the questionnaire was measured using Cronbach's a coefficient.

\section{Results}

\section{Subjects characteristics}

1) Demographic characteristics

Of the total 100 subjects, 26 (26\%) were male and $74(74 \%)$ were female. Table 1 shows demographic characteristic of the participants. The most common age group was 50-59 years. Distribution by age was 1 (1\%) under 40-year, 23 (23\%) under 50-year, 47 (47\%) under 60-year, 23 (23\%) under 70-year, $6(6 \%)$ over 70-year. Regarding occupation, housewife was the most frequent occupation.
Table 1. Demographic Characteristics of Subjects

\begin{tabular}{lcc}
\multicolumn{1}{c}{ Variable } & Number & $\%$ \\
\hline Sex & & \\
$\quad$ Male & 26 & 26 \\
Female & 74 & 74 \\
\hline Age & & \\
$\quad<40$ & 1 & 1 \\
$40 \sim 49$ & 23 & 23 \\
$50 \sim 59$ & 47 & 47 \\
$60 \sim 69$ & 23 & 23 \\
$\geq 70$ & 6 & 6 \\
\hline Occupation & & \\
Inoccupation & 8 & 8 \\
Housewife & 46 & 46 \\
Self employmentor Service & 15 & 15 \\
Student or etc. & 5 & 5 \\
Office worker & 15 & 15 \\
Engineer & 8 & 8 \\
Professional & 5 & 5 \\
\hline$\quad$ Total & 100 & 100 \\
\hline$\quad$ &
\end{tabular}

2) Korean Medicine Hospital use-related characteristics As seen in Table 2, after cancer diagnosis, 10 patients (10\%) visited the Korean Medicine Hospital for the first time, and 90 patients (90\%) came to the Korean Medicine Hospital via a local clinic or general hospital. As for the year of diagnosis, it was less than 1 year in 15 (15\%), 1 2 years in $50(50 \%), 3 \sim 4$ years in $21(21 \%)$, more than 4 years in $14(14 \%)$. Regarding the duration of admission, it was less than 1 week in $15(15 \%)$, $1 \sim 2$ weeks in $49(49 \%), 3 \sim 4$ weeks in $8(8 \%)$, $4 \sim 8$ weeks in $8(8 \%)$, and more than 8 weeks in $20(20 \%)$. About the number of admission, 31 patients $(31 \%)$ were hospitalized once, 33 patients (33\%) were hospitalized 2 to 5 times, 14 patients (14\%) were hospitalized between more than 5 times to within 1 year, and 21 patients (21\%) were hospitalized for multiple years. 
Survey on Satisfaction with Korean Medicine Treatment and Motives for Visiting Korean Medicine Hospital for Cancer Patients: Report of 100 Cases

Of the 100 respondents, 23 (23\%) answered that they had visited Korean Medicine Hospital in the past. And among this 23 patients, 8 (29.6\%) were very satisfied with the Korean medical service they received in the past, 11 (40.7\%) were satisfied, and 8 (29.6\%) answered 'neutral'. No one answered that they were dissatisfied or very dissatisfied (Table 2).

As for the route that led to the choice of Korean Medicine Hospital, there were 11 patients (11.8\%) choosing through 'Reporting on TV, newspapers, the Internet, etc.', 2 patients (2.2\%) through 'Seeing review of others on website or etc., 61 patients (65.6\%) through 'Recommendations from others', 18 patients (19.4\%) through 'Search by oneself', and $1(1.1 \%)$ other has previously known about the hospital. When asked about willingness to recommend to others, 97 (97\%) answered 'yes' and $3(3 \%)$ said 'Don't know' (Table 2).

The distribution of satisfaction scores was highly lean toward the satisfaction direction. The answers to overall satisfaction were; 'very satisfied' in 43 patients (43\%), 'satisfied' in 48 patients (48\%), 'neutral' in $9(9 \%)$, 'dissatisfied' and 'very dissatisfied' in $0(0 \%)$. Regarding cost of treatment, $21(21.6 \%)$ of respondents answered that the cost of hospital treatment was very satisfactory, $38(38.0 \%)$ said that was satisfactory, $33(34.0 \%)$ told that was moderate (neutral), $3(3.1 \%)$ responded that was unsatisfactory and $2(2.1 \%)$ answered that was very unsatisfactory. About the intention to reuse, 97 respondents (97\%) answered yes, 1 (1\%) answered no, and $2(2 \%)$ answered that they didn't know. Regarding the intention to visit outpatient after discharge, $79(80.6 \%)$ respondents answered yes, 1 (1.0\%) answered no, and $18(18.4 \%)$ answered that they didn't know (Table 2).

As for the motivation for selecting Korean Medicine Hospital after cancer diagnosis, 43 patients (43.4\%) answered that it was 'For enhancing cancer-related immune system or reducing adverse events after chemotherapy'. 35 patients (35.4\%) answered that it was 'For preventing metastasis or recurrence', 32 patients (32.3\%) answered that it was 'For symptom management', 3 patients (3\%) answered that it was 'For treating cancer only with Korean medicine' (Table 3).

Regarding the reason for choosing 'Daejeon Korean Medicine Hospital' among Korean Medicine Hospital, the respond 'Because the skills of the medical staff were excellent' was 4.39 (0.81), which had the highest average score. Next, the scores are listed in order, 'Because the hospital staff are kind' was 4.37 (0.82), 'Because academic research and drug development are being actively carried out as university hospital' was 4.14 (0.87), 'Because hospital's facilities and equipment are satisfactory' was 4.01 (0.92), 'Because it is easy to access or transportation is convenient' was 3.78 (1.20), 'Because the hospital staff are well aware of the patient's information because of previous visits' 3.41 (1.30), and 'Because the cost of treatment is cheap' 2.76 (1.05) (Table 4).

The most satisfied treatment item during admission was 'Acupuncture' (71.8\%), followed by 'moxibustion' (28.2 \%), 'Manual therapy' (16.5\%), 'Herbal medicine' (15.3\%) (Table 5). 
Hyeon-muk Oh · Sul-ki Kim $\cdot$ Chan-ran Park $\cdot$ Myung-hyun Ko $\cdot$ So-jung Park,

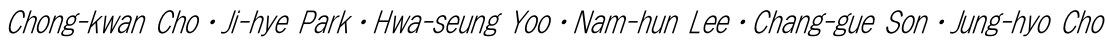

Table 2. General Characteristics of Subjects Visiting Korean Medicine Hospital of Cancer Treatment

\begin{tabular}{|c|c|c|c|}
\hline \multirow{2}{*}{\multicolumn{2}{|c|}{ Variable }} & \multicolumn{2}{|c|}{ Total } \\
\hline & & Number & $\%$ \\
\hline \multirow{2}{*}{$\begin{array}{c}\text { Immediate visit after cancer } \\
\text { diagnosis }\end{array}$} & Yes & 10 & 10 \\
\hline & No & 90 & 90 \\
\hline \multirow{4}{*}{ Year of diagnosis } & Within 1 year & 15 & 15 \\
\hline & $1 \sim 2$ years & 50 & 50 \\
\hline & $3 \sim 4$ years & 21 & 21 \\
\hline & $>4$ years & 14 & 14 \\
\hline \multirow{5}{*}{ Duration of admission } & Within 1 week & 15 & 15 \\
\hline & 1 2 weeks & 49 & 49 \\
\hline & $3 \sim 4$ weeks & 8 & 8 \\
\hline & $4 \sim 8$ weeks & 8 & 8 \\
\hline & $>8$ weeks & 20 & 20 \\
\hline \multirow{4}{*}{ Number of admission } & 1 time & 31 & 31 \\
\hline & $2 \sim 5$ times & 33 & 33 \\
\hline & $>5$ times within 1 year & 14 & 14 \\
\hline & $\geq 1$ year & 21 & 21 \\
\hline \multirow{3}{*}{$\begin{array}{l}\text { Previous experience of Koran } \\
\text { medical hospital treatment }\end{array}$} & Yes & 27 & 27 \\
\hline & No & 73 & 73 \\
\hline & Total & 100 & 100 \\
\hline \multirow{2}{*}{\multicolumn{2}{|c|}{ Variable }} & \multicolumn{2}{|c|}{ Total } \\
\hline & & Number & $\%$ \\
\hline \multirow{3}{*}{$\begin{array}{l}\text { Past experience of Korean } \\
\text { medical hospital }\end{array}$} & Yes & 27 & 27 \\
\hline & No & 73 & 73 \\
\hline & Total (missing) & $100(0)$ & 100 \\
\hline \multirow{6}{*}{$\begin{array}{l}\text { Satisfaction of past experience } \\
\text { of Korean medical hospital }\end{array}$} & Very satisfied & 8 & 29.6 \\
\hline & Satisfied & 11 & 40.7 \\
\hline & Neutral & 8 & 29.6 \\
\hline & Dissatisfied & 0 & 0 \\
\hline & Very dissatisfied & 0 & 0 \\
\hline & Total (missing) & $27(73)$ & 100 \\
\hline \multirow{6}{*}{$\begin{array}{c}\text { The route that led to the } \\
\text { choice of Korean medical } \\
\text { hospital }\end{array}$} & Reporting on TV, newspapers, the Internet, etc. & 11 & 11.8 \\
\hline & Seeing review of others on website or etc. & 2 & 2.2 \\
\hline & Recommendations from others & 61 & 65.6 \\
\hline & Search by oneself & 18 & $19 . .4$ \\
\hline & Etc. & 1 & 1.1 \\
\hline & Total (missing) & $93(7)$ & 100 \\
\hline \multirow{4}{*}{$\begin{array}{l}\text { Willingness to recommend to } \\
\text { others }\end{array}$} & Yes & 97 & 97 \\
\hline & No & 0 & 0 \\
\hline & Don't know & 3 & 3 \\
\hline & Total (missing) & $100(0)$ & 100 \\
\hline
\end{tabular}


Survey on Satisfaction with Korean Medicine Treatment and Motives for Visiting Korean Medicine Hospital for Cancer Patients: Report of 100 Cases

\begin{tabular}{|c|c|c|c|}
\hline \multirow{2}{*}{\multicolumn{2}{|c|}{ Variable }} & \multicolumn{2}{|c|}{ Total } \\
\hline & & Number & $\%$ \\
\hline \multirow{6}{*}{$\begin{array}{l}\text { General satisfaction of } \\
\text { medical service }\end{array}$} & Very satisfied & 43 & 43 \\
\hline & Satisfied & 48 & 48 \\
\hline & Neutral & 9 & 9 \\
\hline & Dissatisfied & 0 & 0 \\
\hline & Very dissatisfied & 0 & 0 \\
\hline & Total (missing) & $100(0)$ & 100 \\
\hline \multirow{6}{*}{ Satisfaction of treatment cost } & Very satisfied & 21 & 21.6 \\
\hline & Satisfied & 38 & 39.2 \\
\hline & Neutral & 33 & 34.0 \\
\hline & Dissatisfied & 3 & 3.1 \\
\hline & Very dissatisfied & 2 & 2.1 \\
\hline & Total (missing) & $97(3)$ & 100 \\
\hline \multirow{4}{*}{ Intention to reuse } & Yes & 97 & 97 \\
\hline & No & 1 & 1 \\
\hline & Don't know & 2 & 2 \\
\hline & Total (missing) & $100(0)$ & 100 \\
\hline \multirow{4}{*}{$\begin{array}{c}\text { Intention to visit outpatient } \\
\text { after discharge }\end{array}$} & Yes & 79 & 80.6 \\
\hline & No & 1 & 1.0 \\
\hline & Don't know & 18 & 18.4 \\
\hline & Total (missing) & $98(2)$ & 100 \\
\hline
\end{tabular}

Table 3. Motivation for Selecting Korean Medicine Hospital for Cancer Treatment

\begin{tabular}{|c|c|c|}
\hline Item description & $\begin{array}{l}\text { Number of } \\
\text { respondents }\end{array}$ & $\%$ \\
\hline For treating cancer only with Korean medicine & 3 & 3 \\
\hline For symptom management & 32 & 32.3 \\
\hline For preventing metastasis or recurrence & 35 & 35.4 \\
\hline $\begin{array}{l}\text { For enhancing cancer-related immune system or reducing adverse events after } \\
\text { chemotherapy }\end{array}$ & 43 & 43.4 \\
\hline Total (No response) / Percent in case & $99(1)$ & 100 \\
\hline
\end{tabular}

SD : standard deviation 
Table 4. Motivation for Selecting 'Daejeon Korean Medicine Hospital' for Cancer Treatment

\begin{tabular}{|c|c|c|}
\hline Item description & $\begin{array}{l}\text { Number of } \\
\text { respondents }\end{array}$ & Mean (SD) \\
\hline Because the skills of the medical staff were excellent & 96 & $4.39(0.81)$ \\
\hline Because hospital's facilities and equipment are satisfactory & 95 & $4.01(0.92)$ \\
\hline $\begin{array}{l}\text { Because academic research and drug development are being actively carried } \\
\text { out as university hospital }\end{array}$ & 99 & $4.14(0.87)$ \\
\hline Because the hospital staff are kind & 97 & $4.37(0.82)$ \\
\hline Because the cost of treatment is cheap & 92 & $2.76(1.05)$ \\
\hline Because it is easy to access or transportation is convenient & 95 & $3.78(1.20)$ \\
\hline $\begin{array}{l}\text { Because the hospital staff are well aware of the patient's information because } \\
\text { of previous visits }\end{array}$ & 88 & $3.41(1.30)$ \\
\hline 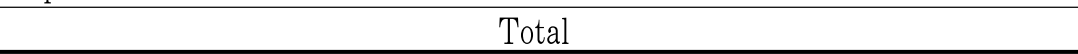 & 100 & \\
\hline
\end{tabular}

Table 5. Satisfaction by Treatment Item

\begin{tabular}{ccc} 
Treatment item & $\begin{array}{c}\text { Number of } \\
\text { respondents }\end{array}$ & $\%$ \\
\hline Acupucture & 61 & 71.8 \\
Pharmacoacupuncture & 3 & 3.5 \\
Cupping & 6 & 7.1 \\
Moxibustion & 24 & 28.2 \\
Herbal medicine & 13 & 15.3 \\
Physical therapy & 3 & 3.5 \\
Manual therapy & 14 & 16.5 \\
\hline Total (No response) / Percentage in case & $85(15)$ & 100 \\
\hline
\end{tabular}

\section{Satisfaction for medical service}

As a result of surveying the satisfaction of each medical service use unit through doctor service and medical service using procedures, the factor-wise internal consistency was 0.850 for doctor service, 0.861 for medical service using procedure, indicating high level of confidence.

Regarding the satisfaction degree of doctor service, the average of satisfaction degree of doctor service was $4.80 \pm 0.40$, and the satisfaction with the item description 'response and sufficient explanation for usual questions from doctor' was found to be the highest at $4.86 \pm 0.38$ (Table 6 ). The average level of satisfaction degree of using procedure was $4.68 \pm 0.44$, and the satisfaction with the convenience of reception was the highest at $4.78 \pm 0.46$ (Table 7).

The results of comparing the differences in satisfaction degree with doctor services by gender, age, and occupation of the patients were as follows. Satisfaction degree of doctor service was $4.89 \pm 0.24$ for men and $4.77 \pm 0.44$ for women. Satisfaction degree of using procedure was $4.82 \pm 0.29$ for men and $4.62 \pm 0.47$ for women. The p-values were 0.075 and 0.007 , respectively, indicating that males were more satisfied than females (Table 8).

About the differences by age, the satisfaction 
Survey on Satisfaction with Korean Medicine Treatment and Motives for

Visiting Korean Medicine Hospital for Cancer Patients: Report of 100 Cases

degree of doctor services under the age of 40 was the highest at 5.00, but only in one patient. And those over the age of 70 were found to be as high as 4.96 \pm 0.10 , and those aged 40-49 years, 60-69 years, 50-59 years as followed. Those over 70 years old showed the highest level of satisfaction degree of using procedure, with $4.90 \pm 0.24$, followed by 40-49 years old, 50-59 years old, 60-69 years old, and under 40 years old. The respective $\mathrm{p}$-values were 0.717 and 0.236 , representing that there was no difference in satisfaction degree by age (Table 9).

Regarding the differences by occupation, the satisfaction degree of doctor service was highest in the case of engineers or students and etc. at 5.00, and the satisfaction degree of using procedure was the highest in the case of engineers at $4.93 \pm 0.12$, with p-values of 0.545 and 0.474 , respectively. There was no difference in satisfaction according to occupation (Table 10).

Table 6. Satisfaction Degree of Doctor Service

\begin{tabular}{ccc} 
Item description & Number & Mean (SD) \\
\hline Knowledge and skill of doctor & 100 & $4.72(0.55)$ \\
Feedback from patients & 100 & $4.85(0.44)$ \\
Response and sufficient explanation for usual questions & 100 & $4.86(0.38)$ \\
Sufficient explanation for treatment, prognosis & 100 & $4.78(0.52)$ \\
\hline Total & 100 & $4.80(0.40)$ \\
\hline
\end{tabular}

SD : standard deviation

Table 7. Satisfaction Degree of Using Procedure

\begin{tabular}{ccc}
\hline Item description & Number & Mean (SD) \\
\hline Accessibility to doctor & 100 & $4.69(0.56)$ \\
Reasonable waiting time & 100 & $4.62(0.55)$ \\
Speed of staff service & 100 & $4.63(0.60)$ \\
Convenience of reception & 100 & $4.78(0.46)$ \\
Post reception waiting time & 100 & $4.66(0.57)$ \\
\hline Total & 100 & $4.68(0.44)$ \\
\hline
\end{tabular}

SD : standard deviation

Table 8. Satisfaction Degree by Sex

\begin{tabular}{cccccccc} 
Division & & Number & Mean & SD & t score & DF & p-value \\
\hline \multirow{2}{*}{ Satisfaction degree of doctor service } & Male & 26 & 4.89 & 0.24 & \multirow{2}{*}{1.806} & \multirow{2}{*}{80.826} & \multirow{2}{*}{0.075} \\
& Female & 74 & 4.77 & 0.44 & & \\
\multirow{2}{*}{ Satisfaction degree of using procedure } & Male & 26 & 4.82 & 0.29 & \multirow{2}{*}{2.509} & \multirow{2}{*}{72.105} & \multirow{2}{*}{0.007} \\
\cline { 2 - 7 } & Female & 74 & 4.62 & 0.47 & \multirow{2}{*}{. }
\end{tabular}

$\mathrm{SD}:$ standard deviation, DF : degree of freedom 
Hyeon-muk Oh · Sul-ki Kim · Chan-ran Park · Myung-hyun Ko $\cdot$ So-jung Park, Chong-kwan Cho $\cdot$ Ji-hye Park $\cdot$ Hwa-seung Yoo $\cdot$ Nam-hun Lee $\cdot$ Chang-gue Son $\cdot J u n g-h y o ~ C h o$

Table 9. Satisfaction Degree by Age

\begin{tabular}{ccccccc} 
Division & & Number & Mean & SD & F-statistics & p-value \\
\hline & $<40$ & 1 & 5.00 & 0.00 & & \\
Satisfaction degree of doctor service & $40 \sim 49$ & 23 & 4.85 & 0.27 & & \\
& $50 \sim 59$ & 47 & 4.76 & 0.50 & 0.526 & 0.717 \\
& $60 \sim 69$ & 23 & 4.80 & 0.29 & & \\
& $\geq 70$ & 6 & 4.96 & 0.10 & & \\
\hline \multirow{5}{*}{ Satisfaction degree of using procedure } & $<40$ & 1 & 4.20 & 0.00 & & \\
& $40 \sim 49$ & 23 & 4.80 & 0.34 & & \\
& $50 \sim 59$ & 47 & 4.63 & 0.47 & 1.411 & 0.236 \\
& $60 \sim 69$ & 23 & 4.62 & 0.49 & & \\
\hline
\end{tabular}

SD : standard deviation

Table 10. Satisfaction Degree by Occupation

\begin{tabular}{|c|c|c|c|c|c|c|}
\hline \multicolumn{2}{|c|}{ Division } & Number & Mean & SD & F-statistics & $\mathrm{p}$-value \\
\hline \multirow{7}{*}{$\begin{array}{l}\text { Satisfaction degree of } \\
\text { doctor service }\end{array}$} & Inoccupation & 8 & 4.91 & 0.19 & \multirow{7}{*}{0.836} & \multirow{7}{*}{0.545} \\
\hline & Housewife & 46 & 4.80 & 0.34 & & \\
\hline & Self employment or Service & 15 & 4.67 & 0.58 & & \\
\hline & Student or etc. & 5 & 5.00 & 0.00 & & \\
\hline & Office worker & 15 & 4.83 & 0.29 & & \\
\hline & Engineer & 8 & 5.00 & 0.00 & & \\
\hline & Professional & 5 & 4.69 & 0.70 & & \\
\hline \multirow{7}{*}{$\begin{array}{l}\text { Satisfaction degree of } \\
\text { using procedure }\end{array}$} & Inoccupation & 8 & 4.83 & 0.33 & \multirow{7}{*}{0.935} & \multirow{7}{*}{0.474} \\
\hline & Housewife & 46 & 4.61 & 0.51 & & \\
\hline & Self employment or Service & 15 & 4.56 & 0.45 & & \\
\hline & Student or etc. & 15 & 4.88 & 0.27 & & \\
\hline & Office worker & 3 & 4.73 & 0.36 & & \\
\hline & Engineer & 8 & 4.93 & 0.12 & & \\
\hline & Professional & 5 & 4.78 & 0.36 & & \\
\hline
\end{tabular}

SD : standard deviation

\section{Discussion}

Patient satisfaction and medical service quality has recently been regarded as an important issue in evaluating the performance of health care providers $^{10}$. Patient perspectives of the quality of health care services provided are somewhat subjective given that patients have limited know ledge of health care-related information. Health care providers can identify the service design and delivery improvements that contribute to patient satisfaction and revisit intention ${ }^{11}$. Consequently, patients' satisfaction is an important criterion for assessing the performance of the medical services and determinant of compliance with the doctor ${ }^{12}$. Higher patient's satisfaction levels contribute to the results in terms 
Survey on Satisfaction with Korean Medicine Treatment and Motives for

Visiting Korean Medicine Hospital for Cancer Patients: Report of 100 Cases

of improved prognosis, less negligence lawsuits. Therefore, patient satisfaction is a predictor of future health ${ }^{13}$.

However, research on Korean Medical services for cancer patients is insufficient, so it was determined that such a study was necessary to increase patients' satisfaction and promote reuse of Korean Medicine Hospital. Accordingly, our research team conducted this study to investigate the satisfaction of cancer patients using a questionnaire that modified the basic items of SERVQUAL, a measure for evaluating service quality, according to Korean Medicine Hospital ${ }^{14}$.

The demographic characteristics showed that women in their 50s accounted for a large proportion and most of the occupations are housewives. It is thought that middle-aged women choose inpatient treatment because they have more time than others.

Considering the general characteristics of Korean Medicine Hospitals, most of respondents went general hospital and then visit Korean Medicine Hospital after cancer diagnosis. A large proportion of patients answered that the reason for visiting Korean Medicine Hospital was to prevent metastasis or recurrence, and to enhance cancer-related immune system or to reduce adverse events after chemotherapy, suggesting that they are visiting Korean Medicine Hospital for an supplementary purpose in the course of cancer treatment.

In general, the period of hospitalization on cancer patients was limited to 2-3 weeks, so the most patients received inpatient treatment for 2-3 weeks. And the number of admission over 2 times was $69 \%$, showing high reuse rate. It can be confirmed that $97 \%$ of those who intend to reuse in the future and $79 \%$ of those who intend to use it as an outpatient are consistent with the above results. It can be confirmed that $97 \%$ of those who intend to reuse in the future and $79 \%$ of those who intend to visit outpatient are consistent with the above results. It was found that recommendations from others were the most likely route for patients to choose Korean Medicine Hospitals. Hospital visiting from TV, newspaper, and Internet promotions or review on website was low, indicating that cancer treatment by Korean Medicine was not sufficiently publicized. Therefore, it is necessary to promote advantages of Korean Medicine cancer treatment through various methods in the future.

The motivation for visiting our 'Daejeon Korean Medicine Hospital' among various Korean Medicine Hospital was that the skill of the medical staff and the kindness of the hospital staff played an important role. These results represent that patients are positively accepting the effect of Korean Medicine on managing side effects in the course of cancer therapy (reference). Also, this results consistent with the fact that the importance of friendly service is being emphasized ${ }^{15}$. In the case of Korean Medicine, there are many treatment items that cannot be covered by public health insurance, so there are many cases where patients feel burdened by cost. In fact, $35.2 \%$ answered that they were not satisfied with the cost of treatment. Acupuncture treatment was the most satisfactory treatment item among the treatment items $(71.8 \%)$, as various research reported that acupuncture was effective for the symptoms of cancer patients after surgery, chemotherapy and radiotherapy ${ }^{16}$.

Because there was no significant difference between each item in doctor service satisfaction and satisfaction with the using procedure, no meaningful results could be obtained. Satisfaction with doctor service 
(4.80) was higher than satisfaction with using procedure (4.68). In the doctor service, males showed higher satisfaction than females according to gender, but there were no significant differences according to gender, age, and occupations in the remaining results. Most of the inpatients tend to be friendly to doctors and hospital staff, so there is a limit to check the defects to be supplemented in this satisfaction survey. According to a study examining 420 cancer patients' satisfaction in university hospital, it was found that the quality of medical services which are medical expertise, administrative service had a significant effect on patient satisfaction ${ }^{17}$. There seems to be no difference between general hospital and Korean Medical Hospital in the factors determining the patient satisfaction.

Taken together, most of the patients admitted to Korean Medicine Hospital for cancer treatment showed a tendency to be satisfied with the treatment and services of Korean Medicine Hospital. Satisfaction with treatment methods tends to be heavily weighted towards acupuncture and moxibustion, so various attempts to use various Korean Medical services such as pharmacoacupuncture and herbal medicine should be continued. The excellence and effectiveness of Korean Medicine on cancer treatment should be promoted through various methods such as advertising and research. In addition, it is necessary to continuously conduct research on cancer treatment, so that it can go one step further and become a major hospital in cancer treatment. Also if the shortcomings are supplemented, more people will be able to receive high-quality Korean Medical services, and it is thought that patient satisfaction will also increase.

This study has several limitations. 1) This study was conducted on three Korean Medicine Hospitals affiliated with the Daejeon university, so it is difficult to evaluate the level of medical service of Korean Medicine Hospital for cancer patients based on the results of this study alone. 2) In addition, most of the patients who responded to the questionnaire were middle-aged women. Future studies are needed to expand the range of patients. 3) In Korean Medicine Hospitals, treatment items could be different depending on patients' personal insurance. This is important bias that can affect satisfaction degree in relation to cost. 4) Characteristics and statistical information according to type of cancer is not presented. This should be considered in future studies.

The results of this study are meaningful in confirming the positive perception of cancer patients on Korean Medicine cancer treatment. We could see that the satisfaction with Korean medicine treatment of cancer patients is relatively high. To improve the quality of services continuous research is needed in the future.

\section{Acknowledgments}

None. No funding to declare.

\section{Conflicts of Interest}

No conflicts of interest.

\section{Author contribution statement}

Hyeon-Muk Oh wrote the main manuscript text, and conducted survey. Seul-Gi Kim and Chan-Ran Park conducted survey. So-Jung Park, Ji-Hye Park performed a statistical analysis. Chong-Kwan Cho, Hwa-Seung Yoo, Nam-Heon Lee, Chang-Gue Son 
Survey on Satisfaction with Korean Medicine Treatment and Motives for

Visiting Korean Medicine Hospital for Cancer Patients: Report of 100 Cases

and Jung-Hyo Chosupervised the manuscript, and directed final version of all contents. All authors reviewed and approved this manuscript.

\section{References}

1. Mattiuzzi C, Lippi G. Current cancer epidemiology. J Epidemiol Glob Health 2019;9(4):217-22.

2. Miller KD, Nogueira L, Mariotto AB, Rowland $\mathrm{JH}$, Yabroff KR, Alfano CM, et al. Cancer treatment and survivorship statistics, 2019. CA Cancer J Clin 2019;69(5) :363-85.

3. Schirrmacher V. From chemotherapy to biological therapy: A review of novel concepts to reduce the side effects of systemic cancer treatment. Int $J$ Oncol 2019;54(2) :407-19.

4. Kwon HK, Kim JS, Yoo HS. Review for the current status of cancer complementary and alternative medicine in the world. $J$ Korean Tradit Oncol 2009;14(1):1-11.

5. Choi YJ, Lee JS, Cho SH. Use of Korean Medicine among cancer patients. J Korean Med 2012; 33(3) : 46-53.

6. Park BK, Lee JH, Cho CK, Shin HK, Eom SK, Yoo HS. Systemic review of clinical studies about oriental medical treatment of cancer in Korea. J intern Korean med 2008;29(4):1061-74.

7. Kim GT, Hwang YS, Park NG, Park SH, Lee JM, Lee CH, et al. Six Cases of Breast Cancer Patients Treated with Korean Medical Hospitalization for Chemotherapy Adverse Effects. $J$ Korean Obstet Gynaecol 2020;33(2):124-44.

8. Bae KR, Kim JH, Park JH, Park SJ, Kang HJ, Cho CK, Yoo HS. Two-cases of Reduction of Side Effects of Surgery and Radiation Therapy in Retroperitoneal Liposarcoma Treated with Traditional Korean Medicine. $J$ Korean Tradit
Oncol 2015;20(2):37-49.

9. Park JM, You SJ, Choi SY, Lyu YS. Survey of Motives for Visiting Oriental Medical Hospital and Satisfaction with Oriental Medical Care for Cancer Patients: Report of 22 Cases. J Oriental Neuropsychiatry 2015;26(1):23-38.

10. Vogus TJ, McClelland LE. When the customer is the patient: Lessons from healthcare research on patient satisfaction and service quality ratings. Human Resource Management Review 2016; 26(1) :37-49.

11. Bjertnaes OA, Sjetne IS, Iversen HH. Overall patient satisfaction with hospitals: effects of patient-reported experiences and fulfilment of expectations. BMJ Qual Saf 2012;21(1):39-46.

12. Batbaatar E, Dorjdagva J, Luvsannyam A, Savino MM, Amenta P. Determinants of patient satisfaction: a systematic review. Perspect Public Health 2017;137(2):89-101.

13. Shirley ED, Sanders JO. Patient satisfaction: implications and predictors of success. $J$ Bone Joint Surg 2013:95(10):69.

14. Parasuraman A, Zeithaml VA, Berry L. SERVQUAL: A multiple-item scale for measuring consumer perceptions of service quality 1988; 64(1) :12-40.

15. Berry LL, Danaher TS, Chapman RA, Awdish RL. Role of kindness in cancer care. $J$ Oncol Pract 2017:13(11):744-50.

16. O’Regan D, Filshie J. Acupuncture and cancer. Auton Neurosci 2010;157(1-2):96-100.

17. Yang JH, Song TK, Chang DM. Effects of Medical Service Quality on the Customer Satisfaction and Intention of Revisit in Cancer Patients. The Korea Contents Association 2012; $12(12): 269-81$. 


\section{한방병원에 내원한 암환자 100 예에 대한 한방치료 만족도 및 내원 동기 조사연구}

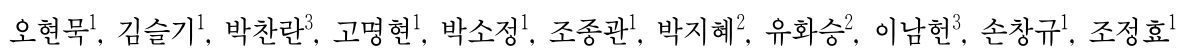
${ }^{1}$ 대전대학교 부속 대전한방병원, ${ }^{2}$ 대전대학교 부속 서울한방병원 내과, ${ }^{3}$ 대전대학교 부속 천안한방병원 내과

초 록

목적: 본 연구는 대전대학교 부속 한방병원에서 암을 주소로 입원치료를 받은 환자를 대상으로 내원 동기 및 만족도를 평 가하고자 한다.

방법: 총 100 명의 입원환자를 대상으로 의료서비스 만족도 측정을 위한 설문조사를 실시하였다. 통계분석은 독립표본 T검 정(Independent $\mathrm{t}$-test), 분산 분석(ANOVA)을 사용하였다.

결과: 암환자들이 한방병원에 내원한 주된 동기는 '암의 전이 및 재발을 예방하기 위해서'로 조사되었다. 환자들은 한방 치 료 중 침과 뜸에 대해 가장 높은 만족도를 보였다. 5점 척도로 구성된 만족도 조사에서 한의사 서비스와 관련된 만족도는 평균 4.80점, 의료서비스 이용 관련 만족도는 4.68점으로 나타났다.

결론: 대부분의 암환자는 한방병원의 의료서비스에 만족하는 것으로 나타났고 성별, 연령 및 직업에 따른 한방 의료서비스 만족도에는 유의한 차이가 없었다.

중심어: 환자 만족도, 한의학, 암 